\title{
Intracellular Magnesium and Adipokines in Umbilical Cord Plasma and Infant Birth Size
}

\author{
JUNJI TAKAYA, FUMIKO YAMATO, HIROHIKO HIGASHINO, AND KAZUNARI KANEKO \\ Department of Pediatrics, Kansai Medical University, Moriguchi, Osaka 570-8506, Japan
}

\begin{abstract}
Many epidemiologic studies have disclosed that restricted fetal growth has been associated with an increased risk of insulin resistance in adulthood. We studied the relationship of intracellular magnesium $\left(\left[\mathrm{Mg}^{2+}\right]_{\mathrm{i}}\right)$ in cord blood platelets to adipocytokine and birth size. The subjects were 20 infants with small for gestational age (SGA) and 45 infants with appropriate for gestational age (AGA). By using a fluorescent probe, we examined $\left[\mathrm{Mg}^{2+}\right]_{\mathrm{i}}$ of platelets in the cord blood. Cord plasma insulin, IGF-I, ghrelin, adiponectin, plasminogen activator inhibitor-1 (PAI-1), and leptin levels were determined with the use of ELISA. Mean $\left[\mathrm{Mg}^{2+}\right]_{\mathrm{i}}$ was lower in the SGA than in the AGA groups $(p<0.001)$. Adiponectin and IGF-I were also lower in the SGA than in the AGA, whereas PAI-1 was higher in the SGA. $\left[\mathrm{Mg}^{2+}\right]_{\mathrm{i}}$ was significantly correlated with birth weight, birth length, and adiponectin. Birth weight was also correlated with cord plasma IGF-I, adiponectin, and leptin. Quantitative insulin sensitivity check index (QUICKI) was lower in the SGA group than in the AGA group. $\left[\mathrm{Mg}^{2+}\right]_{\mathrm{i}}$ and adiponectin were correlated with QUICKI in all subjects. $\left[\mathrm{Mg}^{2+}\right]_{\mathrm{i}}$, as well as leptin and IGF-I, reflect the extent of fetal growth. Decreased $\left[\mathrm{Mg}^{2+}\right]_{\mathrm{i}}$ may be involved in the underlying processes to insulin resistance. (Pediatr Res 62: 700-703, 2007)
\end{abstract}

$\mathrm{T}$ here is no doubt that low birth weight is associated with adult disorders characterized by insulin resistance such as type 2 diabetes, hypertension, dyslipidemia, and coronary heart disease $(1,2)$. It has been proposed that this association results from fetal programming in response to the intrauterine environment (3). Intracellular magnesium $\left(\mathrm{Mg}^{2+}\right)_{\mathrm{i}}$ deficiency occurs in patients with diabetes and vascular diseases (4-6). Taken together, these experimental and epidemiologic results suggest that the correlation between $\mathrm{Mg}^{2+}$ and birth weight are important determinants of insulin resistance. We and other investigators reported that insulin could regulate intracellular $\mathrm{Mg}^{2+}\left(\left[\mathrm{Mg}^{2+}\right]_{\mathrm{i}}\right)$ in platelets $(7,8)$. Platelets are often used in the study of cellular cation metabolism in diseases (9), because they are readily available for study and are thought to share a number of features with vascular smooth muscle cells. Human platelets have been shown to have insulin receptors with similar characteristics as those in other cells (10).

$\mathrm{Mg}^{2+}$ is a critical cofactor in numerous enzymatic reactions. However, the role of $\left[\mathrm{Mg}^{2+}\right]_{\mathrm{i}}$ in the pathogenesis of insulin resistance is not known. Moreover, the association

Received February 14, 2007; accepted July 7, 2007.

Correspondence: Junji Takaya, M.D., Department of Pediatrics, Kansai Medical University, 10-15 Fumizonocho, Moriguchi, Osaka 570-8506, Japan; e-mail: takaya@takii.kmu.ac.jp

This work was supported by the Mami Mizutani Foundation. between $\left[\mathrm{Mg}^{2+}\right]_{\mathrm{i}}$ and adipokines, i.e. adipocyte-secreted hormones, has not yet been studied. We previously reported the correlation with $\left[\mathrm{Mg}^{2+}\right]_{\mathrm{i}}$ and birth weight (11). As the next step, we hypothesized that $\left[\mathrm{Mg}^{2+}\right]_{\mathrm{i}}$ may affect metabolic hormones and insulin resistance in infants. We studied the correlation among $\left[\mathrm{Mg}^{2+}\right]_{\mathrm{i}}$, adipokines in cord blood and insulin resistance index.

\section{SUBJECTS AND METHODS}

The study group consisted of 65 singleton subjects with gestational ages ranging from 33 to $41 \mathrm{wk}$, and birth weights ranging from 1332 to $4030 \mathrm{~g}$. Most of these subjects had been previously recruited for an observational study of $\left[\mathrm{Mg}^{2+}\right]_{\mathrm{i}}(11)$. Gestational age was measured by dating the last menstrual period at the time of registration. None of the subjects were treated with medications, including magnesium, and did not show any evidence of endocrine malfunction or recent use of drugs that might potentially alter electrolyte balance. All the mothers were Japanese with no remarkable past medical histories, and they manifested no abnormal findings during pregnancy, such as preeclampsia. Cord blood of diabetic mothers, such as preexisting diabetes and gestational diabetes mellitus, were excluded. Infants were excluded if they had multiple gestation, neural tube defect, chromosomal abnormality, or other severe congenital diseases.

Definition of small and appropriate for gestational age (SGA and AGA). SGA was defined as birth weight below -1.5 standard deviation (SD) of the Japanese standard birth weight curve (Japanese Ministry of Health and Welfare Research Group 1983, revised in 1994) (12). Ponderal index [birth weight (in kilograms) divided by birth length (in meters) cubed] was used as a measure of relative birth weight. Appropriate for gestational age (AGA) was defined as birth weight, birth length, and ponderal index $\geq 10$ th percentile and $\leq 10$ th percentile of the respective mean for the gestational age.

Platelet preparation. Cord blood samples were collected by the Labor Ward staff and kept at $4^{\circ} \mathrm{C}$. Platelets were isolated as previously described (13). Approximately $10 \mathrm{~mL}$ of cord blood was drawn into $3.8 \%$ (wt/vol) acid citrate buffer (10:1, vol/vol) and was centrifuged at $200 \mathrm{~g}$ for $10 \mathrm{~min}$ at room temperature. The platelet-rich plasma was decanted, further centrifuged at $1000 \mathrm{~g}$ for $10 \mathrm{~min}$, and the cells were washed three times in HEPES buffer solution (HBS) containing $140 \mathrm{mM} \mathrm{NaCl}, 5 \mathrm{mM} \mathrm{KCl}, 25 \mathrm{mM}$ glucose, $1 \mathrm{mM}$ $\mathrm{MgCl}_{2}, 1 \mathrm{mM} \mathrm{NaH} \mathrm{PO}_{4}, 25 \mathrm{mM}$ HEPES (pH 7.2), and $0.2 \mathrm{mM}$ EGTA. EGTA was omitted from the third washing, and $0.1 \%$ fatty-acid free BSA was added. Platelets were counted in a Celltac counter (Nihon Kohden, Tokyo, Japan). Unless otherwise indicated, platelets were suspended in HBS at a concentration of $2-3 \times 10^{7}$ platelets/mL. Platelets were studied within $4 \mathrm{~h}$ after blood drawing.

Plasma was separated immediately, stored at $-80^{\circ} \mathrm{C}$, and thawed only once before analysis.

Measurements of $\left[\mathrm{Mg}^{2+}\right]_{i}$ concentrations. $\left[\mathrm{Mg}^{2+}\right]_{\mathrm{i}}$ concentrations were measured with a Hitachi F-2000 fluorescence spectrophotometer (Hitachi Instruments, Tokyo, Japan) by using a $\mathrm{Mg}$-specific fura- 2 probe as described by Raju et al. (14). Briefly, a $2 \mu \mathrm{M}$ quantity of mag-fura-2/acetoxymethyl dye was added to the platelet suspension and incubated at $37^{\circ} \mathrm{C}$ for $30 \mathrm{~min}$. After loading the dye, the platelets were washed twice with HBS, the fura dye was

Abbreviations: AGA, appropriate for gestational age; $\mathbf{M g}^{2+}$, magnesium; $\left[\mathrm{Mg}^{2+}\right]_{\mathrm{i}}$, intracellular magnesium; PAI-1, plasminogen activator inhibitor-1; QUICKI, quantitative insulin sensitivity check index; SGA, small for gestational age 
Table 1. Clinical and analytical characteristics in SGA and AGA

\begin{tabular}{lcc}
\hline & SGA $(n=20)$ & AGA $(n=45)$ \\
\hline Gender (male/female) & $9 / 11$ & $22 / 23$ \\
Gestational age (wk) & $37.3 \pm 0.6^{*}$ & $39.3 \pm 0.2$ \\
Birth weight $(\mathrm{g})$ & $2110 \pm 79^{*}$ & $3110 \pm 41$ \\
Length $(\mathrm{cm})$ & $5.6 \pm 0.5^{*}$ & $0.1 \pm 0.2$ \\
Ponderal index $\left(\mathrm{kg} / \mathrm{m}^{3}\right)$ & $4.0 \pm 0.8$ & $4.6 \pm 1.4$ \\
Glucose $(\mathrm{mmol} / \mathrm{L})$ & $3.25 \pm 0.38$ & $3.01 \pm 0.21$ \\
Insulin $(\mathrm{pmol} / \mathrm{L})$ & $69 \pm 28$ & $55 \pm 15$ \\
QUICKI & $0.35 \pm 0.02^{* *}$ & $0.41 \pm 0.01$ \\
\hline
\end{tabular}

$* p<0.001, * * p<0.01$.

removed by centrifugation, and the platelets were resuspended in HBS. The excitation wavelengths were set at $335 / 370 \mathrm{~nm}$, and the emission wavelength was $510 \mathrm{~nm}$. Each intracellular ionic concentration was calculated as described $(14,15)$ by using dissociation constant $(\mathrm{Kd})=1500(\mu \mathrm{M})$. The maximum intensities were determined by disrupting the cells with $0.1 \%$ Triton in the presence of $30 \mathrm{mM} \mathrm{MgCl} 2$. The minimum intensities were the values determined in the presence of $60 \mathrm{mM}$ EDTA. $\mathrm{MnCl}_{2}(0.05 \mathrm{mM})$ was used to quench the fluorescence from extracellular dye according to the methods of $\mathrm{Ng}$ et al. (16).

ELISA assay. Cord plasma glucose was measured using a standard assay. Cord plasma leptin levels were determined with the use of a commercially available ELISA (Immuno-Biologic Laboratories Co., Ltd., Gunma, Japan) with a detection limit of $195 \mathrm{pg} / \mathrm{mL}$ [intra- and interassay coefficients of variation $(\mathrm{CV})$ of $6.9 \%$ and $7.7 \%$, respectively]. Plasma IGF-I, and adiponectin assays were performed using commercially available ELISA (R \& D Systems, Minneapolis, MN) with a detection limit of $7 \mathrm{pg} / \mathrm{L}$ and $0.80 \mathrm{ng} / \mathrm{mL}$ (intra- and interassay $\mathrm{CV}$ of $4.3-5.3 \%$ and $8.1-9.8 \%$, respectively). Plasma insulin concentrations were determined with the use of a commercially available ELISA (Linco Research, Inc., St. Charles, MO) with a detection limit of $1.08 \mathrm{pmol} / \mathrm{L}$ (intra- and interassay CV of $5.3 \%$ and $9.8 \%$, respectively). Plasma plasminogen activator inhibitor-1 (PAI-1) assay was performed using a commercially available ELISA (Hyphen Bio Med., Neuvillesur-Oise, France) with a detection limit of $0.5 \mathrm{ng} / \mathrm{mL}$ (intra- and interassay $\mathrm{CV}$ of $5 \%$ and $7.5 \%$, respectively). Plasma desacyl ghrelin assay was performed using a commercially available ELISA (SCETI Co., Ltd., Tokyo, Japan) with a detection limit of $2.5 \mathrm{fmol} / \mathrm{mL}$ (intra- and interassay CV of $5 \%$ and $10 \%$, respectively).

Quantitative insulin sensitivity check index (QUICKI). QUICKI was calculated from the cord insulin and glucose levels instead of their fasting concentrations using the following formula: QUICKI $=1 /[\log$ plasma insulin $(\mu \mathrm{U} / \mathrm{mL})+\log$ fasting plasma glucose $(\mathrm{mg} / \mathrm{dL})]$.

Chemicals. All chemicals were purchased from Sigma Chemical Co. (St. Louis, MO), unless stated otherwise. Mag-fura-2/acetoxymethyl was from Molecular Probes (Eugene, OR).

Statistical analysis. Data were expressed as the mean \pm SD. Statistical significance was assessed using ANOVA, followed by Tukey-Kramer honestly significant difference test. Outcome variables were compared between the subgroups (AGA and SGA) using $t$ tests. The correlations between cord blood $\left[\mathrm{Mg}^{2+}\right]_{\mathrm{i}}$ levels and birth size, IGF-I, and insulin, respectively were examined by linear regression and Spearman rank correlation coefficient analyses. A value of $p<0.05$ was considered significant. All statistical analyses were performed using StatView software (SAS Institute Inc., Cary, NC).

Ethical considerations. The study protocol was approved by the ethics committee of the Kansai Medical University. Written informed parental consent was obtained before recruitment.

\section{RESULTS}

Profile of each group. Table 1 summarizes the clinical characteristics and anthropometric indices of SGA and AGA. No statistical differences between the groups were observed for plasma glucose, insulin levels, and ponderal index. QUICKI was lower in the SGA than in the AGA group. Gestational age in the SGA group was shorter than that of the AGA group. Each group did not significantly differ in terms of maternal age and parity. Table 2 shows the comparison of hormone concentrations between the groups. Plasma $\mathrm{Mg}^{2+}$ and leptin concentrations did not differ significantly between
Table 2. Comparison of the metabolic hormones between SGA and $A G A$

\begin{tabular}{lcc}
\hline & SGA $(n=20)$ & AGA $(n=45)$ \\
\hline$\left[\mathrm{Mg}^{2+}\right] \mathrm{i}(\mu \mathrm{mol} / \mathrm{L})$ & $284 \pm 33 \dagger$ & $468 \pm 132$ \\
Adiponectin $(\mu \mathrm{g} / \mathrm{mL})$ & $11.4 \pm 1.8^{* *}$ & $17.1 \pm 1.0$ \\
IGF-I $(\mathrm{ng} / \mathrm{mL})$ & $14.3 \pm 2.1^{* *}$ & $30.3 \pm 2.2$ \\
Leptin $(\mathrm{pg} / \mathrm{mL})$ & $845 \pm 215$ & $1260 \pm 137$ \\
Ghrelin $(\mathrm{fmol} / \mathrm{mL})$ & $76.8 \pm 11.0$ & $53.7 \pm 5.1$ \\
PAI-1 $(\mathrm{ng} / \mathrm{mL})$ & $13.2 \pm 2.5^{*}$ & $8.0 \pm 0.9$ \\
Plasma $\mathrm{Mg}(\mathrm{mg} / \mathrm{dL})$ & $1.45 \pm 0.07$ & $1.48 \pm 0.04$ \\
\hline$* p<0.05, * * p<0.005, \dagger p<0.0001$. &
\end{tabular}

Table 3. Correlation between $\left[\mathrm{Mg}^{2+}\right] \mathrm{i}$ and anthropometric indices and other metabolic hormones

\begin{tabular}{lcc}
\hline \multicolumn{1}{c}{ Parameters } & $r$ & $p$ Value \\
\hline Gestational age & 0.485 & $<0.0001$ \\
Birth weight & 0.618 & $<0.0001$ \\
Length & 0.476 & $<0.0001$ \\
Ponderal index & 0.053 & 0.691 \\
Glucose & 0.014 & 0.908 \\
Insulin & -0.138 & 0.253 \\
IGF-I & 0.272 & 0.030 \\
QUICKI & 0.592 & $<0.0001$ \\
Leptin & 0.073 & 0.547 \\
Ghrelin & -0.227 & 0.064 \\
Adiponectin & 0.246 & 0.040 \\
PAI-1 & -0.180 & 0.138 \\
\hline
\end{tabular}

the SGA and AGA groups, whereas serum adiponectin, IGF-I and $\left[\mathrm{Mg}^{2+}\right]_{\mathrm{i}}$ were significantly lower in the SGA group. In contrast, PAI-1 was significantly higher in the SGA group than in the AGA group (Table 2). There was no difference of adipocytokines value between genders, including leptin value.

Correlation and multiple regression analysis of plasma adipokines and $\left[\mathrm{Mg}^{2+}\right]_{i}$. The relationship between $\left[\mathrm{Mg}^{2+}\right]_{\mathrm{i}}$ and metabolic hormones or anthropometric indices are summarized in Table $\left.3 . \mathrm{Mg}^{2+}\right]_{\mathrm{i}}$ did not correlate significantly with ghrelin, insulin, leptin, or PAI- $1 .\left[\mathrm{Mg}^{2+}\right]_{\mathrm{i}}$ was significantly associated with gestational age, adiponectin $(r=0.246$, $p=0.04)$ (Fig. 1A), IGF-I $(r=0.272, p<0.03)$, QUICKI $(r=$ $0.592, p<0.0001$ ) (Fig. 1B) and anthropometric indices including birth weight (Fig. 1C) and length (Fig. 1D). The birth weight was by far the most powerful determinant of $\left[\mathrm{Mg}^{2+}\right]_{\mathrm{i}}$ levels. Birth weight was positively correlated with adiponectin, leptin, and IGF-I as well as $\left[\mathrm{Mg}^{2+}\right]_{\mathrm{i}}$ (Table 4).

Correlation of insulin resistant parameter and anthropometric indices. QUICKI was positively correlated with gestational age $(p<0.0001)$, birth weight $(p<0.0001)$, length $(p<$ $0.0001)$, head $(p<0.01)$ and chest circumstance $(p<0.0005)$, and adiponectin $(p<0.0005)$, as well as $\left[\mathrm{Mg}^{2+}\right]_{\mathrm{i}}(p<0.0001)$. QUICKI was negatively correlated with ghrelin $(p<0.005)$.

\section{DISCUSSION}

We previously reported that $\left[\mathrm{Mg}^{2+}\right]_{\mathrm{i}}$ measured in umbilical cord platelets correlated significantly with infant birth weight and birth length (11) and further extended the study to show the correlation with $\left[\mathrm{Mg}^{2+}\right]_{\mathrm{i}}$, insulin sensitivity index, and adipokines. As $\left[\mathrm{Mg}^{2+}\right]_{\mathrm{i}}$ plays a promotive role in fetal growth, low $\left[\mathrm{Mg}^{2+}\right]_{\mathrm{i}}$ may be partly responsible for SGA. The fact that the prenatal environment can modify adult diseases is now 

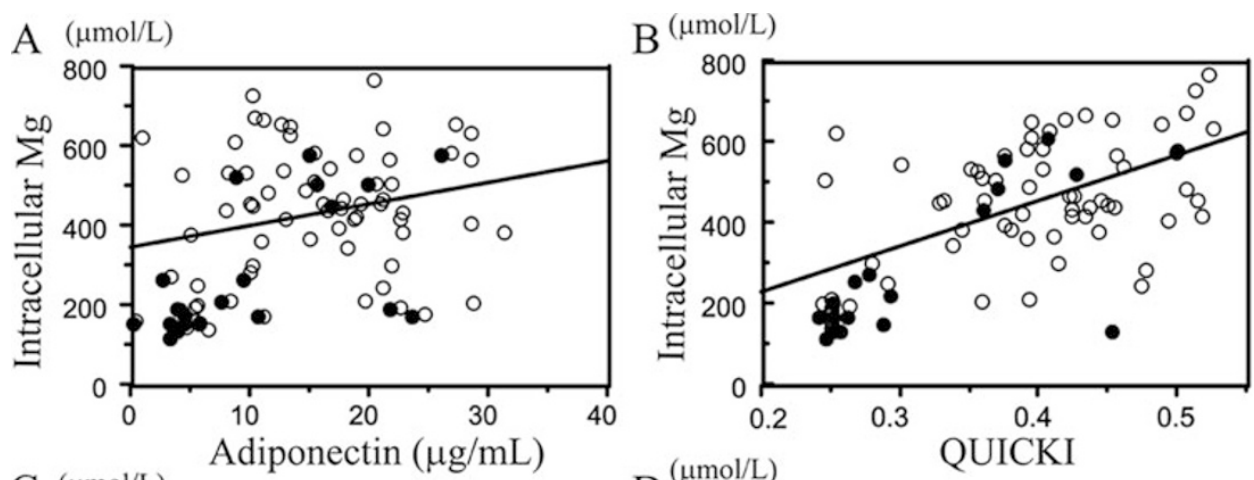

Figure 1. (A) The correlation between intracellular $\mathrm{Mg}^{2+}$ and adiponectin. The basal level of intracellular $\mathrm{Mg}^{2+}$ of cord blood platelets is significantly correlated with adiponectin $(p<0.001, r=0.59)$. $\bigcirc$, AGA; SGA. $(B)$ The correlation between intracellular $\mathrm{Mg}^{2+}$ and QUICKI. The basal level of intracellular $\mathrm{Mg}^{2+}$ of cord blood platelets is significantly correlated with birth weight $(p<0.001, r=$ 0.59). $\bigcirc$, AGA; $\bigcirc$, SGA. (C) The correlation between intracellular $\mathrm{Mg}^{2+}$ and birth weight. The basal level of intracellular $\mathrm{Mg}^{2+}$ of cord blood platelets is significantly correlated with birth weight $(p<$ $0.001, r=0.61)$. $\bigcirc$, AGA; $\bigcirc$, SGA. Figure was adapted from (11), and another three subjects were added. $(D)$ The correlation of intracellular $\mathrm{Mg}^{2+}$ and birth length. The basal level of intracellular $\mathrm{Mg}^{2+}$ of cord blood platelets is significantly correlated with birth weight $(p<0.001, r=$

0.48). $\bigcirc$, AGA;, SGA.
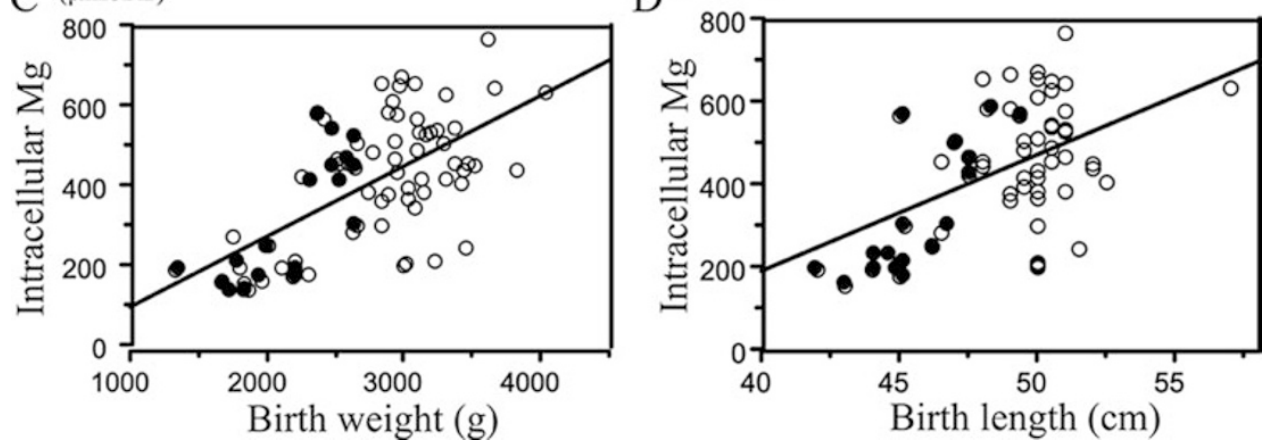

Table 4. Correlation between birth weight and parameters

\begin{tabular}{lcc}
\hline Parameters & $r$ & $p$ Value \\
\hline$\left[\mathrm{Mg}^{2+}\right] \mathrm{i}$ & 0.618 & $<0.0001$ \\
Adiponectin & 0.477 & $<0.0001$ \\
IGF-I & 0.469 & $<0.0001$ \\
Leptin & 0.361 & 0.003 \\
Ghrelin & -0.341 & 0.006 \\
PAI-1 & -0.225 & 0.068 \\
\hline
\end{tabular}

firmly established and is supported by both epidemiologic data $(1,2)$ and experimental studies (17). However, the processes that explain the link between reduced fetal growth and insulin resistance or glucose intolerance in adulthood are not fully understood. $\mathrm{Mg}^{2+}$ deficiency occurs in adult patients with diabetes mellitus and vascular diseases $(4,5)$. We also reported that children with diabetes and obesity have $\left[\mathrm{Mg}^{2+}\right]_{\mathrm{i}}$ deficiency (6). We further tested whether the origin of $\left[\mathrm{Mg}^{2+}\right]_{\mathrm{i}}$ deficiency may start from fetal life. Low $\left[\mathrm{Mg}^{2+}\right]_{\mathrm{i}}$ may be set in SGA (18) by genetic factors or intrauterine environment. Taken together, we hypothesized that decreased $\left[\mathrm{Mg}^{2+}\right]_{\mathrm{i}}$ might underlie the initial pathophysiologic events leading to insulin resistance.

A growing body of evidence suggests that adiponectin may also play a role in the development of insulin resistance (19). Adipokines are considered the group of adipose secreted proteins. It has direct actions on the liver, skeletal muscle, and vasculature, with prominent roles to improve hepatic insulin sensitivity, to increase fuel oxidation (via up-regulation of AMP-activated protein kinase activity) and to decrease vascular inflammation (20). In fact, it has been reported that circulating adiponectin in obese or diabetic rodents is associated with a reduction in endogenous glucose production and an increase in insulin sensitivity (19). In the present study, we have confirmed that plasma adiponectin levels of the cord blood were lower in the SGA group than in the AGA group and were correlated with $\left[\mathrm{Mg}^{2+}\right]_{\mathrm{i}}$. Lower adiponectin and $\left[\mathrm{Mg}^{2+}\right]_{\mathrm{i}}$ levels in the SGA group may suggest that the SGA group is less sensitive to insulin than in the AGA group. In addition, the higher levels of PAI-1 in the SGA group may suggest that the SGA subjects have potent tendencies to insulin resistance. However, there was no difference between the AGA and SGA groups in ponderal index, which is often used as a marker of infant fat mass. This may be due, at least in part, to the different distribution of neonatal adipose tissue, which, in contrast to adults, is mainly subcutaneous. Furthermore, birth weight was well correlated with IGF-I, leptin, and adiponectin, but not with insulin levels in the cord blood, which is in agreement with the findings of the previous report (21). Concerning fetal life, it has been postulated that not only nutritional and environmental factors during pregnancy, but also hormonal factors, are implicated in fetal growth (22-24) in addition to genetic predisposition.

Because measurement of glucose tolerance and insulin sensitivity is practically difficult and ethically not permissible in newborns, we instead quantified QUICKI calculated by cord plasma insulin and glucose levels to assess insulin resistance in fetuses. The ghrelin and adiponectin levels as well as $\left[\mathrm{Mg}^{2+}\right]_{\mathrm{i}}$ correlated positively with QUICKI, a marker of insulin resistance (25). Mean QUICKI levels in the SGA group were significantly lower than in the AGA group. Previously, surrogate indices such as homeostasis model assessment of insulin resistance or fasting glucose-to-insulin ratio in different situations have been reported be useful as parameter for insulin resistance in adults (25), while there are discussions on the validity of these markers in children (26). Although, we checked the homeostasis model assessment of insulin resistance $(p=0.44)$ and fasting glucose-to-insulin ratio $(p=$ 0.09 ), still QUICKI showed a significantly better linear correlation with the $\left[\mathrm{Mg}^{2+}\right]_{\mathrm{i}}$. Log-transformation of data of in- 
sulin and glucose values may improve the correlation of the parameters in cord blood. Nonetheless, surrogate indexes for insulin sensitivity, especially in cord blood, need to be studied further. In addition, the levels of $\left[\mathrm{Mg}^{2+}\right]_{i}$ might depend on different population of platelets, which are isolated by each protocol. The study of platelet population and $\left[\mathrm{Mg}^{2+}\right]_{\mathrm{i}}$ needs to be clarified in future investigations.

In conclusion, $\left[\mathrm{Mg}^{2+}\right]_{\mathrm{i}}$ of the cord blood platelet as well as adiponectin may be a marker of early fetal growth. Low $\left[\mathrm{Mg}^{2+}\right]_{\mathrm{i}}$ may represent the prenatal programming of insulin resistance. Undernourished fetuses make metabolic adaptations that benefit them in the short term by increasing fuel availability, although these adaptations may become persistent throughout life, resulting in insulin resistance. Our results indicate a possible role of $\left[\mathrm{Mg}^{2+}\right]_{\mathrm{i}}$ in fetal life for future disorders characterized by insulin resistance.

Acknowledgments. The authors thank the doctors and midwives of the Labor Ward of our hospital and Inoue Ladies Clinic for taking cord blood samples. We also thank Dr. Yohnosuke Kobayashi, Professor Emeritus of Kansai Medical University, for his fruitful discussion and Kaori Naito for her editorial assistance.

\section{REFERENCES}

1. Barker DJ, Bull AR, Osmond C, Simmonds SJ 1990 Fetal and placental size and risk of hypertension in adult life. BMJ 301:259-262

2. Hales CN, Barker DJ, Clark PM, Cox LJ, Fall C, Osmond C, Winter PD 1991 Fetal and infant growth and impaired glucose tolerance at age 64. BMJ 303:1019-1022

3. Barker DJ 1995 Intrauterine programming of adult disease. Mol Med Today $1: 418-423$

4. Shechter M, Merz CN, Rude RK, Paul-Labrador M, Meisel SR, Shah PK, Kaul S 2000 Low intracellular magnesium levels promote platelet-dependent thrombosis in patients with coronary artery disease. Am Heart J 140:212-218

5. Nadler JL, Malayan S, Luong H, Shaw S, Natarajan RD, Rude RK 1992 Intracellular free magnesium deficiency plays a key role in increased platelet reactivity in type II diabetes mellitus. Diabetes Care 15:835-841

6. Takaya J, Higashino H, Kotera F, Kobayashi Y 2003 Intracellular magnesium of platelets in children with diabetes and obesity. Metabolism 52:468-471

7. Takaya J, Higashino H, Miyazaki R, Kobayashi Y 1998 Effects of insulin and insulin-like growth factor-1 on intracellular magnesium of platelets. Exp Mol Pathol 65:104-109
8. Hwang DL, Yen CF, Nadler JL 1993 Insulin increases intracellular magnesium transport in human platelets. J Clin Endocrinol Metab 76:549-553

9. Resnick LM, Gupta RK, Bhargava KK, Gruenspan H, Alderman MH, Laragh JH 1991 Cellular ions in hypertension, diabetes, and obesity. Hypertension 17:951-957

10. Trovati M, Anfossi G, Cavalot F, Massucco P, Emanuelli G 1988 Insulin directly reduces platelet sensitivity to aggregating agents. Diabetes 37:780-786

11. Takaya J, Yamato F, Higashino H, Kobayashi Y 2004 Ralationship of intracellular magnesium of cord blood platelets to birth weight. Metabolism 53:1544-1547

12. Nishida H, Sakane M, Kurachi K, Asada A, Kubo S, Funakawa H 1984 [Fetal growth curve of Japanese]. Acta Neonat Jpn 20:90-97

13. Takaya J, Iwamoto Y, Higashino H, Ishihara R, Kobayashi Y 1997 Increased intracellular calcium and altered phorbol dibutyrate binding to intact platelets in young subjects with insulin-dependent and non-insulin-dependent diabetes mellitus. Metabolism 46:949-953

14. Raju B, Murphy E, Levy LA, Hall RD, London RE 1989 A fluorescent indicator for measuring cytosolic free magnesium. Am J Physiol 256:C540-C548

15. Grynkiewicz G, Poenie M, Tsien RY 1985 A new generation of $\mathrm{Ca}^{2+}$ indicators with greatly improved fluorescence properties. J Biol Chem 260:3440-3450

16. Ng LL, Davies JE, Garrido MC 1991 Intracellular free magnesium in human lymphocytes and the response to lectins. Clin Sci 80:539-547

17. Simmons RA, Templeton LJ, Gertz SJ 2001 Intrauterine growth retardation leads to the development of type 2 diabetes in the rat. Diabetes 50:2279-2286

18. Merialdi M, Carroli G, Villar J, Abalos E, Gülmezoglu AM, Kulier R, de Onis M 2003 Nutritional interventions during pregnancy for the prevention of treatment of impaired fetal growth: an overview of randomized controlled trials. J Nutr 133:1626S-1631S

19. Yamauchi T, Kamon J, Waki H, Terauchi Y, Kubota N, Hara K, Ide T, Murakami K, Tsuboyama-Kasaoka N, Ezaki O, Akanuma Y, Gavrilova O, Vinson C, Reitman ML, Kagechika H, Shudo K, Yoda M, Nakano Y, Tobe K, Nagai R, Kimura S, Tomita M, Froguel P, Kadowaki T 2001 The fat-derived hormone adiponectin reverses insulin resistance associated with both lipoatrophy and obesity. Nat Med 7:941-946

20. Whitehead JP, Richards AA, Hickman IJ, Macdonald GA, Prins JB 2006 Adiponectin-a key adipokine in the metabolic syndrome. Diabetes Obes Metab 8:264-280

21. Sivan E, Mazaki-Tovi S, Pariente C, Efraty Y, Schiff E, Hemi R, Kanety H 2003 Adiponectin in human cord blood: relation to fetal birth weight and gender. J Clin Endocrinol Metab 88:5656-5660

22. Breschi MC, Seghieri G, Bartolomei G, Gironi A, Baldi S, Ferrannini E 1993 Relation of birthweight to maternal plasma glucose and insulin concentrations during normal pregnancy. Diabetologia 36:1315-1321

23. Verhaeghe J, Van Bree R, Van Herck E, Laureys J, Bouillon R, Van Assche FA 1993 C-peptide, insulin-like growth factors I and II, and insulin-like growth factor binding protein-1 in umbilical cord serum: correlations with birth weight. Am J Obstet Gynecol 169:89-97

24. Boyne MS, Thame M, Bennett FI, Osmond C, Miell JP, Forrester TE 2003 The relationship among circulating insulin-like growth factor (IGF)-I, IGF-binding proteins-1 and -2 , and birth anthropometry: a prospective study. J Clin Endocrinol Metab 88:1687-1691

25. Katz A, Nambi SS, Mather K, Baron AD, Follmann DA, Sullivan G, Quon MJ 2000 Quantitative insulin sensitivity check index: a simple, accurate method for assessing insulin sensitivity in humans. J Clin Endocrinol Metab 85:2402-2410

26. Cutfield WS, Jefferies CA, Jackson WE, Robinson EM, Hofman PL 2003 Evaluation of HOMA and QUICKI as measures of insulin sensitivity in prepubertal children. Pediatr Diabetes 4:119-125 